\title{
CLOCINNAMOX BLOCKS ONLY MU RECEPTORS IRREVERSIBLY: BINDING EVIDENCE
}

Zernig $\mathrm{G}^{*}$, Burke $\mathrm{T},{ }^{*}$ Lewis $\mathrm{JW}^{* *}$, Woods $\mathrm{JH}^{*}, \#$, Departments of Pharmacology* and Psychology\#, University of Michigan, Ann Arbor, MI 48109, USA and Department of Chemistry ${ }^{* *}$, University of Bristol, Bristol, England

In rhesus monkey antinociception experiments, the cinnamoylaminomorphinone opioid antagonist clocinnamox at a dose of $0.1 \mathrm{mg} / \mathrm{kg}$ irreversibly inactivated $88 \%$ of the mu opioid receptor population (as calculated by in vivo Furchgott analysis) whereas kappa receptors remained unaffected (1). In contrast, in vitro radioligand binding assays showed only a moderate mu : delta : kappa selectivity of clocinnamox $(30: 1.5: 1 ;$ ref. 2$)$. This apparent discrepancy was investigated in mice using both in vitro and ex vivo opioid binding studies.

Opioid receptor binding was determined using [ $\left.{ }^{3} \mathrm{H}\right] \mathrm{DAMGO}$ for $\mathrm{mu}-,\left[{ }^{3} \mathrm{H}\right]-\mathrm{p}-\mathrm{Cl}-\mathrm{DPDPE}$ for delta-, and $\left[{ }^{3} \mathrm{H}\right]$ bremazocine in presence of $1 \mu \mathrm{M}$ DAMGO and $1 \mu \mathrm{M}$ DPDPE for kappa opioid receptors in whole mouse brain membranes (buffer: $50 \mathrm{mM}$ Tris-HCl pH 7.4, $0.1 \mathrm{mM}$ phenylmethylsulfonyl fluoride, $1 \%$ dimethyl sulfoxide; $2 \mathrm{~h}$ incubation at $25^{\circ} \mathrm{C}$ ). Clocinnamox showed pseudo- $\mathrm{K}_{\mathrm{i}}$ and $\mathrm{K}_{\mathrm{i}}$ values of $0.25 \mathrm{nM}$ for mu receptors $\left(\mathrm{pK}_{\mathrm{i}} 8.41 \pm 0.07\right.$; Hill slope, $1.0 \pm 0.1$; means \pm S.E.), $1.6 \mathrm{nM}$ for delta receptors ( $\mathrm{pK}_{\mathrm{i}}, 8.09 \pm 0.17$; Hill slope, $0.9 \pm 0.2$ ), and $7.2 \mathrm{nM}$ for kappa receptors $\left(\mathrm{pK}_{\mathrm{i}}, 7.80 \pm 0.9\right.$; Hill slope, $\left.0.1 \pm 0.1\right)$, corresponding to a $29: 5: 1$-selectivity for mu : delta : kappa, thus confirming previous studies. Similarly, clocinnamox' agonistic codeinone derivative, methoclocinnamox (3), yielded pseudo- $\mathrm{K}_{\mathrm{i}}$ and $\mathrm{K}_{\mathrm{i}}$ values of $0.46 \mathrm{nM}$ for mu receptors $\left(\mathrm{pK}_{\mathrm{i}}, 9.34 \pm 0.16\right.$; Hill slope, $\left.1.1 \pm 0.1\right), 4.5 \mathrm{nM}$ for delta receptors $\left(\mathrm{pK}_{\mathrm{i}}, 8.35 \pm 0.21\right.$; Hill slope, $1.2 \pm 0.1$ ), and $29 \mathrm{nM}$ for kappa receptors $\left(\mathrm{pK}_{\mathrm{i}}, 7.54 \pm 0.12\right.$; Hill slope, $1.1 \pm 0.3$ ), corresponding to a $63: 6: 1$-selectivity for mu : delta : kappa. Thus, the present data are in accordance with previously published reports from other laboratories.

In a washout experiment, naltrexone $(1 \mu \mathrm{M})$, clocinnamox and methoclocinnamox (10 $\mathrm{nM}$ and $1 \mu \mathrm{M}$ each) were added to whole mouse brain membranes, incubated for 2 hours (i.e., binding competition experiment condition), then repeatedly washed with 150 volumes/wet weight fresh medium (3) and further incubated for up to $8 \mathrm{~h}$ at $25^{\circ} \mathrm{C}$ to allow for ligand dissociation. Aliquots of these membranes were tested for mu-, delta-, and kappa-opioid receptor binding at the end of the competition binding incubation period, and after $2 \mathrm{~h}$ ( 2 washes) and $8 \mathrm{~h}$ ( 4 washes). Neither the binding inhibition mediated by $10 \mathrm{nM}$ clocinnamox nor that of $1 \mu \mathrm{M}$ clocinnamox could be reversed from mu receptors even after $8 \mathrm{~h}$ washing (e.g., $1 \mu \mathrm{M}, 99.8 \% \rightarrow 94 \%$ ), whereas it was at least partially reversible at delta $(99.7 \% \rightarrow 69 \%)$ and kappa $(86 \%->62 \%)$ receptors. The binding inhibition mediated by methoclocinnamox, however, was at least partially reversible at all three opioid receptor subtypes. Naltrexone-mediated binding inhibition was completely reversed at the first washout period tested, i.e. $2 \mathrm{~h}$ ( 2 washes). In summary, the in vitro binding data indicate that although clocinnamox interacts with all three opioid receptor subtypes, only its interaction with the mu receptor is of an irreversible nature.

Similar results were obtained in ex vivo binding experiments. Mice were treated with $1-10$ $\mathrm{mg} / \mathrm{kg}$ clocinnamox i.p., sacrificed $1 \mathrm{~h}$ to $28 \mathrm{~d}$ later, their brains homogenized and opioid receptor binding measured. Only ex vivo binding to mu receptors was inhibited by clocinnamox, delta and kappa receptor binding remained unaffected even after a clocinnamox pretreatment time of only $1 \mathrm{~h}$. The $\left[{ }^{3} \mathrm{H}\right]$ DAMGO binding inhibition after clocinnamox was due to a decrease in receptor density whereas the affinity of the radioligand for the mu receptors remained essentially unchanged as already demonstrated in a previous study (5). After the acute and dose-dependent decrease of the mu receptor population by clocinnamox ( $1 \mathrm{~h}$ pretreatment; $1 \mathrm{mg} / \mathrm{kg}, 44 \pm 3 \%$ inhibition; $3.2 \mathrm{mg} / \mathrm{kg}, 90 \pm 1 \% ; 10$ $\mathrm{mg} / \mathrm{kg}, 90 \pm 2 \%)$., ex vivo [ $\left[{ }^{3} \mathrm{H}\right]$ DAMGO binding reappeared with a half-lifes of $4.2 \mathrm{~d}($ after $1 \mathrm{mg} / \mathrm{kg}$ clocinnamox), $2.7 \mathrm{~d}(3.2 \mathrm{mg} / \mathrm{kg})$, and $2.8 \mathrm{~d}(10 \mathrm{mg} / \mathrm{kg})$. 
The reappearance of mu opioid receptors was partially blocked by the protein synthesis inhibitor cycloheximide. Following previously published experimental protocols $(6,7)$, a loading dose of $50 \mathrm{mg} / \mathrm{kg}$ cycloheximide and a subsequent administration of $5 \mathrm{mg} /(\mathrm{kg} . \mathrm{h})$ cycloheximide by implanted osmostic minipumps was used to inhibit protein synthesis. Cycloheximide alone did not significantly change ex vivo [ ${ }^{3} \mathrm{H}$ ]DAMGO binding over $48 \mathrm{~h}$ (inhibition $<7 \%$ ), after which the experiment had to be terminated because of the considerable side effects of cycloheximide. Administration of $3.2 \mathrm{mg} / \mathrm{kg}$ clocinnamox alone acutely decreased [ $3 \mathrm{H}$ ]DAMGO binding to $12 \pm 2 \%$ of control . Binding partially recovered within the $48 \mathrm{~h}$ time period, exactly as expected from the previous time course experiments. In contrast, ex vivo [ $\left.{ }^{3} \mathrm{H}\right] \mathrm{DAMGO}$ binding to brain membranes of sham-operated mice (implantation of empty minipumps) did not change over the whole time course. Finally, when mice were given both clocinnamox and cycloheximide, mu receptors acutely were decreased to about the same amount (i.e., $9 \pm 2 \%$ of the control population) as in the mice treated with clocinnamox alone. The reappearance of $\left[{ }^{3} \mathrm{H}\right]$ DAMGO binding, however, was decreased in comparison to the mice treated with clocinnamox alone: After $24 \mathrm{~h},\left[{ }^{3} \mathrm{H}\right] \mathrm{DAMGO}$ binding after clocinnamox alone had returned to $49 \pm 6 \%$ of control, whereas it was $26 \pm 1 \%$ after combined administration of clocinnamox and cycloheximide. The respective values after $48 \mathrm{~h}$ were $62 \pm 4 \%$ for clocinnamox alone and $34 \pm 5 \%$ for the clocinnamox-cycloheximide combination. Ex vivo delta- and kappa opioid receptor binding remained unaffected by either clocinnamox or cycloheximide alone or their combination.

We also compared the time course of ex vivo [ ${ }^{3} \mathrm{H}$ ]DAMGO binding recovery after $3.2 \mathrm{mg} / \mathrm{kg}$ clocinnamox with estimates of $q$, the fraction of available receptors, as determined by Furchgott analysis of data obtained in warm-water tail withdrawal experiments. To that end, published time course experiments (Fig. 5 of ref.8) using morphine as an antagonist were repeated by different experimenters in our laboratory and extended to a time span of 16 days. Data were pooled and analyzed as detailed previously (1) to obtain $\mathrm{q}$, the fraction of available receptors according to Furchgott (9) and Black and Leff (10). $3.2 \mathrm{mg} / \mathrm{kg}$ clocinnamox acutely depressed the q value to 0.3 (1 being the value for the control population). $Q$ values returned with a half-life of $2.0 \mathrm{~d}$, which was close to that of $2.7 \mathrm{~d}$ obtained when analyzing recovery of ex vivo [ $\left.{ }^{3} \mathrm{H}\right] \mathrm{DAMGO}$ binding. Thus, Furchgott analysis of behavioral data again seemed to provide estimates of receptor population changes of reasonably high confidence.

Supported by Austrian Science Foundation Grants J0697-MED and J0882-MED, a NIDA INVEST fellowship (G.Z.), and USPHS Grant DA 00254.

\author{
REFERENCES \\ 1. G.Zernig et al. (1994) J. Pharmacol. Exp. Ther. 268, 57-65 \\ 2. J.W. Lewis et al. (1988) NIDA Res. Monogr. 90,136-143 \\ 3. J.H. Woods et al. (1994) NIDA Res. Monogr., submitted \\ 4. N. Johnson and G.W. Pasternak (1984) Mol. Pharmacol. 26,477-483 \\ 5. T. Burke et al. (1994) J. Pharmacol. Exp. Ther., in press \\ 6. E.E.Quinton and N.R. Kramarcy (1977) Brain Res. 131,184-190 \\ 7. G. Sperk et al. (1978) Brain Res. 159,183-194 \\ 8. S. D. Comer et al. (1992) J. Pharmacol. Exp. Ther. 262, 1051-1056 \\ 9. R. F. Furchgott, Adv. Drug Res. 3, 21-56 (1966) \\ 10. J.W. Black, P. Leff (1983) Proc. R. Soc. Lond. B 220,141-162
}

